\title{
Rendimento, composição tecidual e musculosidade da carcaça de cordeiros Santa Inês alimentados com diferentes níveis de feno de flor-de-seda na dieta
}

\author{
Ana Valéria Mello de Souza Marques ${ }^{1}$, Roberto Germano Costa ${ }^{2}$, Aderbal Marcos de Azevedo \\ Silva $^{3}$, José Morais Pereira Filho ${ }^{3}$, Marta Suely Madruga ${ }^{4}$, Gerson Edmo Lira Filho ${ }^{5}$ \\ ${ }^{1}$ Parte da tese de Doutorado da primeira autora apresentada à Universidade Federal da Paraíba. \\ 2 Departamento de Zootecnia, CFT/UFPB. \\ ${ }^{3}$ Departamento de Medicina Veterinária, CSTR/UFCG. \\ ${ }^{4}$ Departamento de Tecnologia Química e de Alimentos, DTQA/CT/UFPB. \\ 5 Zootecnista, Mestre em Zootecnia, CCA/UFPB.
}

RESUMO - Foi avaliada a inclusão de níveis crescentes de feno de flor-de-seda (Calotropis procera SW) (FFS) em substituição ao feno de sorgo forrageiro (Sorghum bicolor, L.) (FSF) na dieta e seus possíveis efeitos sobre os rendimentos verdadeiro, biológico e comercial, a perda ao resfriamento, o rendimento dos cortes, a composição tecidual e a musculosidade da carcaça de cordeiros Santa Inês. Foram utilizados 24 cordeiros (machos não-castrados) distribuídos em um delineamento inteiramente casualisado, com quatro tratamentos (relações FSF:FFS: 100:0, 66:33, 33:66 e 0:100). Os animais foram abatidos com $30,0( \pm 0,4) \mathrm{kg}$ ou aos 70 dias de experimento. Não houve efeito das relações FSF:FFS na dieta sobre os rendimentos biológico, verdadeiro e comercial, sendo obtidos valores médios de 53,17; 45,97 e 44,34\%, respectivamente. Foram observadas diferenças significativas no peso vivo ao abate, no peso de corpo vazio, nos pesos de carcaça quente e de carcaça fria, no rendimento dos cortes, na composição tecidual e na musculosidade da carcaça. À exceção dos cortes paleta e perna, as variáveis apresentaram valores mais elevados quando fornecidos os menores níveis de FFS na dieta. O feno de flor-de-seda pode ser utilizado na alimentação de cordeiros para produção de carne em proporções de até $16,5 \%$ da dieta (33\% da fração volumosa), pois não ocasiona prejuízo à qualidade da carcaça.

Palavra-chave: área de olho-de-lombo, Calotropis procera SW, carcaça, cortes cárneos

\section{Yield, tissue composition and carcass muscularity of Santa Inês lambs fed diets with different ratios of forage sorghum hay to silk flower hay}

\begin{abstract}
This study evaluated the effects of different dietary ratios of forage sorghum (Sorghum bicolor L) hay (FSH) to silk flower hay (Calotropis procera SW) (SFH) on true, biological, and retail carcass yields, carcass cooling losses, retail cut yields, tissue composition and carcass muscularity of Santa Inês lambs. Twenty-four intact male lambs were assigned to one of the following four treatments: 100:0 FSH:SFH, 66:33 FSH:SFH, 33:66 FSH:SFH, or 0:100 FSH:SFH in a completely randomized design (six animals/treatment). Animals were slaughtered at $30.0 \pm 0.4 \mathrm{~kg}$ of body weight or at 70 days of experiment. There was no effect of treatments on the biological, true, and retail carcass yields, which averaged, respectively $53.17,45.97 \%$, and $44.34 \%$. Except for shoulder clod and leg cuts, increasing the dietary levels of SFH significantly reduced the slaughter body weight, empty body weight, hot and cold carcass weights, retail cut yields, tissue composition, and carcass muscularity. It can be concluded that the inclusion of up to $16.5 \%$ of the diet DM (33\% of the dietary forage) as SFH had no detrimental effect on carcass quality.
\end{abstract}

Key Words: Calotropis procera SW, carcass, loin eye area, meat cuts

\section{Introdução}

Os ovinos deslanados destacam-se pela eficiência em converter forragem em carne de qualidade. Entre as raças de ovinos deslanados exploradas na Região Nordeste, a Santa Inês possui maior velocidade de crescimento, além de maior resistência a parasitoses, alta fertilidade e prolificidade e acentuada habilidade materna, mostrando-se promissora para produção de carne.

Largamente explorados em sistemas intensivos, os ovinos têm se adaptado ao meio ambiente em que predomina a vegetação de caatinga, alimentando-se de espécies abundantes durante seis meses do ano, porém nutricionalmente deficientes no restante do período, influenciando de forma 
negativa e expressiva o desempenho de caprinos e ovinos, limitando sua potencialidade como atividade econômica. Torna-se necessário, portanto, o uso de alternativas alimentares como forma de suplementação nutricional a esses animais objetivando melhorar os índices de produtividade.

A Calotropis procera SW (flor-de-seda ou algodãode-seda), da família Asclepiadácea, destaca-se como uma das espécies arbustivas do semi-árido utilizadas como alternativa alimentar, tanto pela adaptação (mantém-se resistente no período de maior escassez de água) como pela disponibilidade. Abbas et al. (1992) encontraram teores de MS e PB equivalente a 94,62 e 19,4\%, respectivamente, no FFS, confirmando o excelente valor nutritivo da Calotropis procera SW, o que permite sua utilização como alternativa na suplementação protéica/energética de rebanhos no semi-árido. O uso desta planta in natura na alimentação animal é limitado por algumas características dessa planta. Kumar et al. (2001), avaliando as propriedades farmacológicas do látex de Calotropis procera $\mathrm{SW}$, confirmaram a existência de propriedades antiinflamatórias, antifebris e analgésicas. Shihar \& Kumar (2003) afirmaram haver também propriedade antihelmíntica. Sharma (1934) assegura que o látex da Calotropis procera $\mathrm{SW}$ também é usado como abortivo e infanticida. Outra característica do látex dessa planta é sua ação sobre o coração dos mamíferos, aumentando a força das contrações sistêmicas e aumentando a amplitude de contração e relaxamento dos átrios. Mello et al. (2000), analisando galhos e folhas de Calotropis procera SW em estudos fitoquímicos e sua utilização na alimentação caprina, detectaram substâncias ativas como: glicosídeos cardiotônicos, glicosídeos flavônicos, triterpenos, esteróides e polifenóis. Esses autores confirmaram, no entanto, que as plantas desidratadas e picadas não apresentam toxidez, pois, após a dessecação, ocorre perda ou volatização de algumas substâncias ativas, tornando-a menos tóxica.

Segundo Sañudo \& Sierra (1993), a dieta pode alterar as características qualitativas da carcaça e da carne ovina. Com o uso de melhor alimentação e de raças adaptadas à região do semi-árido nordestino com potencial genético para ganho de peso, características relativas ao rendimento e à qualidade de carcaça podem apresentar sensíveis modificações. Este estudo foi realizado com o objetivo de avaliar as características quantitativas da carcaça de cordeiros Santa Inês alimentados com dietas contendo diferentes níveis de feno de flor-de-seda (Calotropis procera SW) em substituição ao feno de sorgo forrageiro (Sorghum bicolor $\mathrm{L}$.).

\section{Material e Métodos}

Foram utilizados 24 cordeiros Santa Inês $(15,7 \pm 1,9 \mathrm{~kg}$ de PV) durante o período de setembro a novembro de 2003. As temperaturas médias do ambiente para máxima e mínima e a umidade relativa foram 33,5 e $25,5^{\circ} \mathrm{C}$ e $49 \%$, respectivamente.

Os animais foram mantidos em regime de confinamento em gaiolas individuais de madeira $\left(1,0 \mathrm{~m}^{2}\right)$ com pisos ripados suspensos, equipadas com comedouros e bebedouros e distribuídas em galpão coberto com telhas de cerâmica.

A flor-de-seda (Calotropis procera $\mathrm{SW}$ ) foi colhida em meio à pastagem nativa e ceifada a uma altura em que o diâmetro do caule estivesse a $5 \mathrm{~cm}$ do solo. $O$ sorgo forrageiro (Sorghum bicolor $\mathrm{L}$ ) foi cultivado em solo de aluvial e ceifado aos 60 dias. No processo de fenação das forragens, as plantas inteiras (caule e folhas) foram trituradas, transportadas para um secador, distribuídas em única camada e revolvidas periodicamente até ficarem com aproximadamente 10\% de umidade (Montardo, 1998). Após desidratação, foram novamente trituradas em máquina forrageira/ picadeira e armazenadas em sacos de ráfia.

Os animais foram everminados e mantidos inicialmente por um período pré-experimental de 14 dias para adaptação às gaiolas, à ração experimental e ao manejo. As dietas foram oferecidas ad libitum duas vezes ao dia. O consumo total de MS foi determinado pelo controle diário do alimento fornecido e das sobras. A quantidade de ração oferecida diariamente foi calculada para permitir sobra de, aproximadamente, $20 \%$ do oferecido.

As dietas foram ajustadas para atender às exigências de proteína e EM descritas pela AFRC (1995) e minerais, segundo o ARC (1980), para ganho de $200 \mathrm{~g} /$ dia. Para ajuste das dietas experimentais, foram utilizados milho triturado, farelo de soja, feno de sorgo forrageiro e/ou feno de flor-deseda, calcário calcítico, sal comum e mistura mineral. A composição bromatológica dos ingredientes e das dietas é apresentada na Tabela 1.

Os teores de MS, PB, EB, FDN, FDA, cinzas, Ca e P (\% da MS) do FSF foram de 90,76; 4, 16; 3,84; 68,90; 42,31; 8,$73 ; 0,40$ e 0,22 e doFFS, de 90,$78 ; 9,40 ; 3,90 ; 56,01 ; 39,63$; 12,$55 ; 2,60$ e 0,22 , respectivamente. Os tratamentos consistiram da substituição do feno de sorgo forrageiro (FSF) pelo feno de flor-de-seda (FFS) nos níveis de 0,33 , 66 e 100\%. Os animais foram pesados a cada 14 dias durante o período experimental e, antes do abate, foram mantidos em jejum de sólidos (18 horas) e em jejum hídrico (12 horas) para determinação do peso vivo ao abate (PVA). 
Tabela 1 - Composição percentual (\%) e bromatológica $(\mathrm{g} / \mathrm{kg})$ das dietas experimentais, com base na MS

Table 1 - Ingredient and chemical composition of the experimentals diets $(\% D M)$

\begin{tabular}{|c|c|c|c|c|}
\hline \multirow[t]{2}{*}{$\begin{array}{l}\text { Ingrediente }(\%) \\
\text { Item }\end{array}$} & \multicolumn{4}{|c|}{$\begin{array}{c}\text { Nível de feno de flor-de-seda (\%) } \\
\text { Silk flower hay }(\%)\end{array}$} \\
\hline & 0 & 33 & 66 & 100 \\
\hline $\begin{array}{l}\text { Feno de sorgo forrageiro } \\
\text { Forage sorghun hay }\end{array}$ & 50,0 & 33,3 & 16,7 & - \\
\hline $\begin{array}{l}\text { Feno de flor-de-seda } \\
\text { Silk flower hay }\end{array}$ & - & 16,7 & 33,3 & 50,0 \\
\hline $\begin{array}{l}\text { Farelo de milho } \\
\text { Corn meal }\end{array}$ & 10,0 & 10,5 & 11,0 & 11,5 \\
\hline $\begin{array}{l}\text { Farelo de soja } \\
\text { Soybean meal }\end{array}$ & 39,0 & 39,0 & 38,5 & 38,0 \\
\hline $\begin{array}{l}\text { Calcário } \\
\text { Limestone }\end{array}$ & 0,50 & 0,0 & 0,0 & 0,0 \\
\hline $\begin{array}{l}\text { Mistura mineral } \\
\text { Mineral mix }\end{array}$ & 0,50 & 0,50 & 0,50 & 0,50 \\
\hline
\end{tabular}

Composição bromatológica $(\mathrm{g} / \mathrm{kg})$

Chemical composition

\begin{tabular}{lcccc}
\hline MS $(D M)$ & 901 & 901 & 901 & 901 \\
PB (CP) & 207 & 216 & 223 & 260 \\
FDN (NDF) & 420 & 400 & 383 & 368 \\
FDA (ADF) & 276 & 272 & 268 & 263 \\
Cinzas (Ash) & 74,4 & 81 & 87,3 & 93,6 \\
$\mathrm{Ca}$ & 4,2 & 6,1 & 9,9 & 13,4 \\
$\mathrm{P}$ & 3,9 & 3,8 & 3,9 & 3,9 \\
\hline
\end{tabular}

${ }^{1}$ Quantidade de elemento por kg de suplemento (composition/kg of the mixture): $\mathrm{Cl}$ - 300 g; S - 12 g; Zn - 4.000 mg; Cu - 600 mg; Mn - 600 mg; Fe - 1.200 mg; Co - 100 mg; I - 120 mg; Se - 12 mg; F - 0,6 g (máx.).

Os cordeiros foram abatidos à medida que atingiram $30 \mathrm{~kg}$ de $\mathrm{PV}$ ou aos 70 dias do experimento para aqueles que não atingiram o peso previsto. $\mathrm{O}$ abate foi realizado por atordoamento com concussão cerebral seguida de sangria pela veia jugular e pela artéria carótida.

Após sangria e esfola, o conteúdo do trato gastrointestinal foi retirado para obtenção do peso de corpo vazio (PCV), calculado como a diferença entre o conteúdo gastrointestinal (CTGI) e o PVA, e para determinação do rendimento de corpo vazio (RCV), que correspondeu à razão entre o peso da carcaça quente (PCQ) e o peso de corpo vazio (PCV) x 100. A carcaça foi separada dos componentes nãocarcaça. As carcaças foram pesadas para obtenção do peso de carcaça quente e determinação do rendimento de carcaça quente (RCQ): razão entre o peso da carcaça quente (PCQ) e o peso vivo ao abate (PVA) x 100. Em seguida, as carcaças foram mantidas durante 24 horas em câmara frigorífica a $4^{\circ} \mathrm{C}$, penduradas pelos tendões da perna em ganchos de metal. Posteriormente, foram pesadas para obtenção do peso (PCF) e rendimento da carcaça fria (razão entre o PCF e o PVA x 100) e determinação da perda por resfriamento: $\mathrm{PPR}=\mathrm{PCQ}-\mathrm{PCF} /$ PCQ x 100. As carcaças foram divididas longitudinalmente ao meio com serra elétrica, dando origem a duas meias-carcaças.
Na meia-carcaça direita resfriada, efetuou-se um corte transversal entre a 12 e e a 13 a costela, expondo a secção transversal do músculo Longissimus dorsi para realização das seguintes medidas sobre sua superfície: medida A ou largura máxima do músculo; medida $\mathrm{B}$ ou profundidade máxima do músculo; menor espessura de gordura sobre o Longissimus dorsi; e maior espessura de gordura sobre o Longissimus dorsi, para determinação da área de olho-delombo (AOL).

Em seguida, a meia-carcaça esquerda foi seccionada em cinco regiões anatômicas, denominadas cortes comerciais: pescoço, paleta, costilhar, lombo e perna. Os cortes foram realizados segundo adaptações das metodologias de Colomer-Rocher et al. (1987), Osório et al. (1998) e Garcia \& Silva Sobrinho (1998). À medida que os cortes foram retirados da carcaça, foram imediatamente pesados e, em seguida, somados os pesos dos cinco cortes obtidos para determinação do peso da meia-carcaça fria reconstituída (PMCFR).

A musculosidade da carcaça foi estimada de forma indireta, utilizando-se três parâmetros que mantêm alta correlação: índice de musculosidade da perna, relação músculo:osso da perna e AOL (De Boer et al., 1974).

A perna, depois de pesada, foi acondicionada em saco plástico, identificada e congelada emfreezer $\left(-20^{\circ} \mathrm{C}\right)$ para posterior dissecação anatômica em músculos, ossos, gorduras e outros tecidos (tendões, vasos, nervos e outros), de acordo com o método descrito por Silva Sobrinho (1999). Após a dissecação, determinou-se a relação músculo:osso e procedeu-se à pesagem e medição do osso do fêmur para determinação do índice de compacidade da perna (ICP) razão entre a largura da perna e o comprimento da perna e do índice de musculosidade da perna, conforme metodologia descrita por Purchas et al. (1991):

$$
\mathrm{IMP}=\sqrt{(\mathrm{P} 5 \mathrm{M} / \mathrm{CF}) / \mathrm{CF}}
$$

$\mathrm{O}$ delineamento experimental utilizado foi o inteiramente casualizado, com quatro tratamentos e seis repetições. Os resultados obtidos foram submetidos às análises de variância e regressão, segundo procedimento GLM do SAS (1996) e, quando pertinente, as médias foram comparadas pelo teste Tukey a 5\% de probabilidade.

\section{Resultados e Discussão}

$\mathrm{Na}$ fase final do ensaio, dois animais do tratamento com $100 \%$ de FFS morreram, o que pode estar associado à baixa ingestão de alimentos, conforme citado por Lira Filho (2004), e à menor resistência desses animais à ação tóxica do FFS em relação aos outros animais desse tratamento. A inclusão do FFS na dieta determinou decréscimo linear nos valores absolutos de PVA, PCV, PCQ e PCF $(\mathrm{P}<0,05)$ e efeito 
quadrático para a perda por resfriamento, entretanto, não influenciou os valores de rendimento de corpo vazio, de carcaça quente e de carcaça fria $(\mathrm{P}>0,05)$ (Tabela 2$)$.

Lira Filho (2004) observou que, apesar de a ingestão de EM pelos animais submetidos às dietas com 66 e 100\% de FFS representar duas vezes o valor da EM para mantença, a partir do 40으 dia experimental, houve redução no ganho de peso médio diário desses animais, com os maiores ganhos nos animais alimentados com as dietas com 0 e 33\% de FFS. Essa redução no ganho de peso, segundo esse autor, poderia estar associada a algum efeito residual de substâncias antinutricionais presentes na forragem (glicosídeos cardiotônicos, glicosídeos flavônicos, triterpenos, esteróides e polifenóis), como mencionado por Mello et al. (2000).

Apesar da redução no ganho de peso, os valores médios obtidos para os rendimentos de carcaça fria $(44,65 \%)$, de carcaça quente $(46,33 \%)$ e de corpo vazio $(53,37 \%)$ podem ser considerados bons e foram próximos aos observados por Silva et al. (2000), Cunha et al. (2001) e Costa et al. (1999), em cordeiros.

Araújo et al. (1999) e Reis et al. (2001), estudando o efeito de diferentes tratamentos nutricionais em cordeiros, também não verificaram diferença significativa para os rendimentos de corpo vazio, de carcaça quente e de carcaça fria e para a perda por resfriamento.

Os valores médios da PPR nos cordeiros alimentados com as dietas com 0,33 e $100 \%$ de FFS variaram de 2,97 a $3,85 \%$ e podem ser considerados normais, segundo a lite- ratura consultada (Carvalho et al., 1980; Reis et al., 2001), pois se encontram na faixa aceitável ( 3,0 a 4,0\%), segundo Sañudo et al. (1981).

A inclusão de níveis crescentes de FFS na dieta de cordeiros Santa Inês determinou decréscimo linear $(\mathrm{P}<0,05)$ para os pesos da meia-carcaça fria, do pescoço, da paleta, das costelas, do lombo e da perna (Tabela 3 ).

Na Figura 1 constam os valores dos rendimentos dos cortes comerciais. Os níveis de FFS resultaram em decréscimo linear $(\mathrm{P}<0,05)$ nos rendimentos de lombo e de costela e acréscimo linear $(\mathrm{P}<0,05)$ no rendimento da perna. Os valores obtidos para os rendimentos de paleta e pescoço não diferiram significaticamente $(\mathrm{P}>0,05)$ entre as dietas avaliadas.

Segundo Osório et al. (2002), quando o peso de carcaça aumenta em valor absoluto, o peso dos cortes comerciais também aumenta em valor absoluto. Quanto ao valor relativo, os resultados obtidos por Colomer \& Diaz (1971) e Osório et al. (2002) comprovaram que, quando o peso de carcaça aumenta, as porcentagens dos cortes comerciais de desenvolvimento precoce (paleta e perna) são reduzidas e as porcentagens dos cortes comerciais de desenvolvimento tardio (costelas, lombo e pescoço) aumentam. Essas informações são semelhantes aos resultados verificados neste experimento, no qual os animais abatidos com maiores pesos ( 0 e $33 \%$ de FFS) apresentaram menor rendimento de um dos cortes mais precoce (perna) e maior rendimento dos cortes tardios (lombo e costelas). O maior rendimento de perna nos animais alimentados com

Tabela 2 - Médias e equações de regressão para as médias do peso vivo ao abate (PVA), dos pesos de corpo vazio (PCV), de carcaça quente (PCQ), de carcaça fria (PCF), dos rendimentos de corpo vazio (RCV), de carcaça quente (RCQ), de carcaça fria (RCF) e da perda por resfriamento da carcaça (PPR) de cordeiros Santa Inês alimentados com dietas com níveis crescentes de feno de flor-de-seda

Table 2 - Means and regression equations for slaughter body weight (SBW), empty body weight (EBW), hot carcass weight (HCW), cold carcass weight (CCW), empty body yield (EBY), hot carcass yield (HCW), cold carcass yield (CCY), and weight loss for cooling (WLC) in carcass of Santa Inês lambs fed diets with different ratios of silk flower hay to forage sorghum hay

\begin{tabular}{|c|c|c|c|c|c|c|c|}
\hline & \multicolumn{4}{|c|}{$\begin{array}{l}\text { Nível de feno de flor-de-seda (\%) } \\
\text { Level of silk flower hay (\%) }\end{array}$} & \multirow[t]{2}{*}{$\begin{array}{l}\text { Equação de regressão } \\
\text { Regression equation }\end{array}$} & \multirow[t]{2}{*}{$\mathrm{P}$} & \multirow[t]{2}{*}{$\mathrm{R}^{2}$} \\
\hline & 0 & 33 & 66 & 100 & & & \\
\hline PVA $(S B W)(\mathrm{kg})$ & 27,47 & 27,82 & 20,27 & 18,44 & $\hat{\mathrm{Y}}=28,67-0,10 \mathrm{x}$ & 0,0001 & 0,56 \\
\hline $\mathrm{PCV}(E B W)(\mathrm{kg})$ & 23,28 & 24,57 & 17,34 & 16,54 & $\hat{Y}=24,30-0,07 x$ & 0,0006 & 0,47 \\
\hline PCQ $(H C W)(\mathrm{kg})$ & 12,62 & 13,50 & 9,17 & 8,48 & $\hat{Y}=13,30-0,04 x$ & 0,0003 & 0,47 \\
\hline $\mathrm{PCF}(C C W)(\mathrm{kg})$ & 11,94 & 13,12 & 8,97 & 8,20 & $\hat{Y}=12,69-0,05 x$ & 0,0006 & 0,50 \\
\hline $\mathrm{RCV}_{(E B Y)}(\%)$ & 54,72 & 54,90 & 52,55 & 51,31 & $\hat{\mathrm{Y}}=53,16$ & 0,7560 & 0,15 \\
\hline RCQ $(H C Y)(\%)$ & 45,67 & 48,55 & 45,13 & 45,95 & $\hat{\mathrm{Y}}=45,97$ & 0,5602 & 0,02 \\
\hline $\mathrm{RCF}(C C Y)(\%)$ & 43,27 & 46,81 & 44,02 & 44,49 & $\hat{\mathrm{Y}}=44,34$ & 0,8993 & 0,001 \\
\hline PPR $(W L C)(\%)$ & 3,74 & 2,97 & 1,83 & 3,85 & $\hat{Y}=3,89-0,063 x+0,0006 x^{2}$ & 0,0093 & 0,55 \\
\hline
\end{tabular}

$\hat{Y}=$ variável dependente; $x$ = nível de feno de flor-de-seda; $R^{2}=$ coeficiente de determinação.

$\hat{\mathrm{Y}}=$ dependent variable, $X=$ independent variable (\% of silk flower hay in the diet), and $R^{2}=$ coefficient of determination 
Tabela 3 - Médias e equações de regressão para os pesos dos cortes comerciais, em relação ao peso da meia-carcaça fria, de cordeiros Santa Inês alimentados com dietas contendo níveis crescentes de feno de flor-de-seda

Table 3 - $\quad$ Means and regression equations for weights of retail cuts as proportion of cold half-carcass weight in Santa Inês lambs fed diets with different ratios of silk flower hay to forage sorghum hay

\begin{tabular}{|c|c|c|c|c|c|c|c|}
\hline & \multicolumn{4}{|c|}{$\begin{array}{c}\text { Nível de feno de flor-de-seda (\%) } \\
\text { Level of silk flower hay (\%) }\end{array}$} & \multirow[t]{2}{*}{$\begin{array}{l}\text { Equação de regressão } \\
\text { Regression equation }\end{array}$} & \multirow[t]{2}{*}{$\mathrm{P}$} & \multirow[t]{2}{*}{$\mathrm{R}^{2}$} \\
\hline & 0 & 33 & 66 & 100 & & & \\
\hline $\mathrm{PM}(C F R)^{1}$ & 5,67 & 6,45 & 4,32 & 4,19 & $\hat{\mathrm{Y}}=6,35-0,023 \mathrm{x}$ & 0,0006 & 0,46 \\
\hline Perna (Leg) $(\%)$ & 1,59 & 2,10 & 1,49 & 1,44 & $\hat{\mathrm{Y}}=2,02-0,06 \mathrm{x}$ & 0,0024 & 0,36 \\
\hline Paleta (Shoulder clod) $(\%)$ & 1,18 & 1,25 & 0,93 & 0,86 & $\hat{\mathrm{Y}}=1,25-0,004 \mathrm{x}$ & 0,0003 & 0,48 \\
\hline Lombo (Loin) (\%) & 0,78 & 0,78 & 0,49 & 0,47 & $\hat{Y}=0,82-0,004 x$ & 0,0005 & 0,45 \\
\hline Costela (Ribs) $(\%)$ & 1,52 & 1,66 & 0,99 & 1,01 & $\hat{Y}=1,63-0,007 x$ & 0,0004 & 0,46 \\
\hline Pescoço (Neck) (\%) & 0,61 & 0,66 & 0,42 & 0,41 & $\hat{\mathrm{Y}}=0,65-0,002 \mathrm{x}$ & 0,0040 & 0,33 \\
\hline
\end{tabular}

1 Peso da meia-carcaça fria reconstituída, $\hat{Y}=$ variável dependente; $X=$ nível de feno de flor-de-seda; $R^{2}=$ coeficientes de determinação.

${ }^{1}$ Weight of reconstituted cold half-carcass, $\hat{Y}=$ dependent variable, $X=$ independent variable (\% of silk flower hay in the diet $) ; R^{2}=$ coefficient of determination.

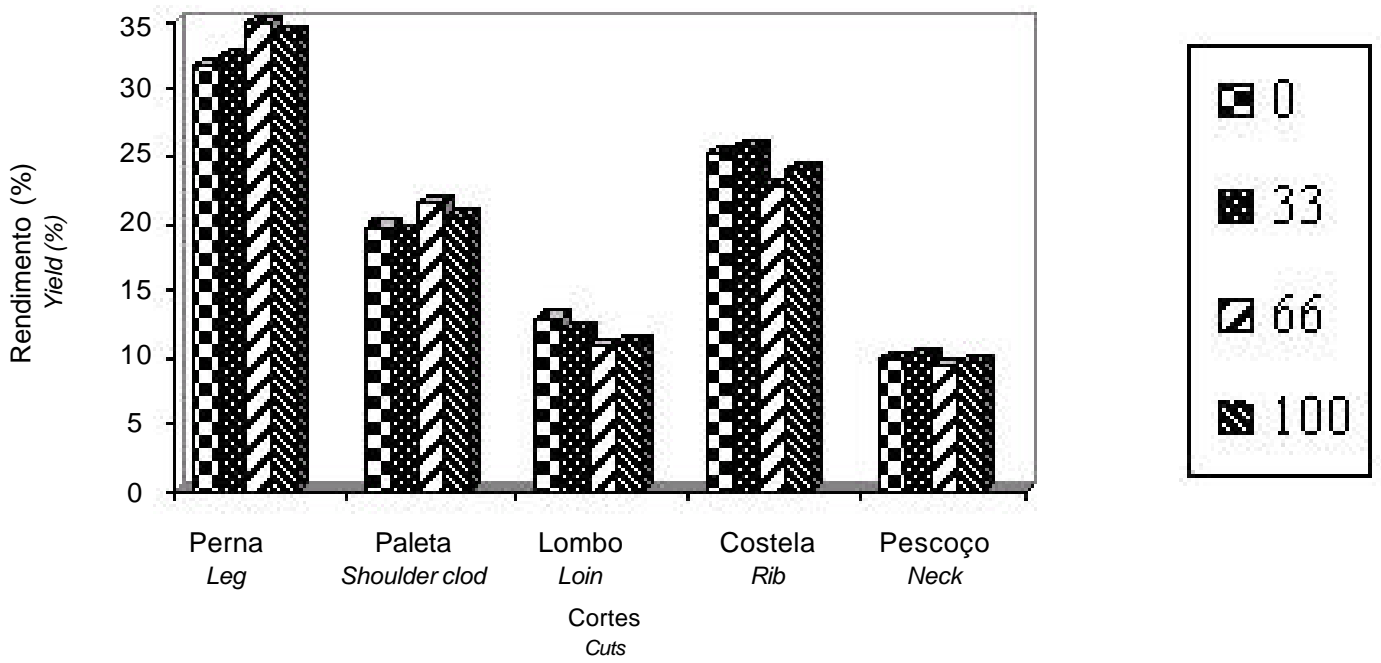

Figura 1 - Rendimento dos cortes comerciais de cordeiros Santa Inês alimentados com dietas contendo níveis crescentes de feno de flor-de-seda FFS (Calotropis procera S.W.).

Figure 1 - Yields of carcass retail cuts of Santa Inês lambs fed diets with different ratios of silk flower hay to forage sorghum hay.

$66 \%$ de FFS provavelmente foi conseqüência do maior peso de osso.

Em todos os tratamentos, a perna, considerada corte mais nobre de carcaças ovinas, contribuiu com o maior rendimento, possivelmente em virtude da maior quantidade de tecido muscular desse corte em comparação aos demais.

Araújo et al. (1999), também estudando o efeito da inclusão de níveis crescentes de feno de maniçoba na dieta de cordeiros sem raça definida abatidos com 22,0 $\pm 3,0 \mathrm{~kg}$, verificaram efeito significativo $(\mathrm{P}<0,05)$ dos tratamentos sobre o rendimento de perna.

A composição tecidual da perna é característica de grande importância na avaliação da qualidade da carcaça. Neste experimento, os níveis de feno de flor-de-seda tiveram efeito linear positivo $(\mathrm{P}<0,05)$ sobre a porcentagem de osso e efeito linear negativo sobre a porcentagem de gordura $(\mathrm{P}<0,05)$. As demais características avaliadas não diferiram significativamente ( $\mathrm{P}>0,05)$ entre as dietas (Tabela 4).

$\mathrm{O}$ aumento do peso de abate dos cordeiros provocou, portanto, diminuição da porcentagem de ossos e aumento da porcentagem de gordura. Apesar do maior peso de abate e do maior peso da perna dos animais dos tratamentos 0 e $33 \%$ de FFS, a porcentagem de músculo não diferiu $(\mathrm{P}>0,05)$ entre os tratamentos. Tulloh (1963) calculou o crescimento relativo de cada um dos três componentes da carcaça em relação à carcaça inteira de ovinos, caprinos e bovinos e concluíram que, com o aumento do peso da carcaça, a proporção de osso diminui, a de músculo permanece constante e a de gordura aumenta, o que difere conforme a espécie. 
Esses resultados são semelhantes aos encontrados por Motta et al. (2001) e Gonzaga et al. (2006), que, estudando a composição tecidual da carcaça de cordeiros Texel e Morada Nova, respectivamente, alimentados com diferentes dietas, concluíram que a proporção de músculos na perna não foi influenciada pela dieta fornecida aos animais.

Os resultados encontrados neste estudo podem ser explicados pelos encontrados por Lira Filho (2004), que observou baixa eficiência de utilização da proteína digestível e redução na ingestão de nutrientes com conseqüente diminuição no ganho de peso nos animais alimentados com dietas com 66 e 100\% de FFS, apesar dos melhores coeficientes de digestibilidade. Segundo esse autor, esse resultado poderia estar associado a algum efeito residual de substâncias antinutricionais presentes na forragem que ocasionaram mobilização da energia disponível para o processo fisiológico de desintoxicação do organismo. De acordo com Cañeque et al. (1989) e Luchiari Filho (2000), a perda de peso associada às deficiências nutricionais afeta todos os tecidos, mas o efeito é maior na gordura, seguida dos musculos e, finalmente, dos ossos.
Na Tabela 5 constam as médias das relações músculo:osso da perna, do índice de musculosidade e da área de olho-de-lombo (AOL). As análises estatísticas comprovam que, com a inclusão de FFS na dieta, houve decréscimo linear $(\mathrm{P}<0,05)$ na relação músculo:osso, no índice de musculosidade da perna e na área de olho-delombo, refletindo a tendência de crescimento heterogônico negativo para os ossos, isogônico para os músculos e heterogônico positivo para a gordura. Purchas et al. (1991) afirmaram que a avaliação da musculosidade da carcaça se baseia na profundidade dos músculos do fêmur em relação ao comprimento desse osso.

Os valores encontrados neste experimento para o índice de musculosidade $(0,31$ a 0,36$)$ foram próximos ao obtido por Silva Sobrinho (1999), em ovinos de diferentes grupos genéticos $(0,45)$.

Gonzaga et al. (2006), avaliando o efeito de diferentes relações volumoso:concentrado na composição tecidual da perna de cordeiros Morada Nova confinados, observaram valor médio de 7,3 para a relação M:O, superior aos deste trabalho. Segundo Purchas et al. (1991), muitas vezes esta

Tabela 4 - Médias e equações de regressão para os rendimentos de osso (RO), de músculo (RM), de gordura (RG) e de outros tecidos (ROT) da carcaça de cordeiros Santa Inês alimentados com dietas contendo níveis crescentes de feno de flor-de-seda

Table 4 - Means and regression equations for yields of bones, muscles, fat and remaining tissues of carcass of Santa Inês lambs fed diets with different ratios of silk flower hay to forage sorghum hay

\begin{tabular}{|c|c|c|c|c|c|c|c|}
\hline & \multicolumn{4}{|c|}{$\begin{array}{c}\text { Nível de feno de flor-de-seda (\%) } \\
\text { Level of silk flower hay }(\%)\end{array}$} & \multirow[t]{2}{*}{$\begin{array}{l}\text { Equação de regressão } \\
\text { Regression equation }\end{array}$} & \multirow[t]{2}{*}{$\mathrm{P}$} & \multirow[t]{2}{*}{$\mathrm{R}^{2}$} \\
\hline & 0 & 33 & 66 & 100 & & & \\
\hline RO (Bone) (\%) & 23,13 & 22,19 & 26,72 & 27,97 & $\hat{\mathrm{Y}}=22,16+0,057 \mathrm{x}$ & 0,001 & 0,46 \\
\hline RM (Muscles) (\%) & 64,46 & 63,47 & 63,43 & 61,79 & $\hat{\mathrm{Y}}=63,41$ & 0,147 & 0,33 \\
\hline RG (Fat) $(\%)$ & 7,68 & 9,81 & 5,75 & 4,70 & $\hat{Y}=8,90-0,038 x$ & 0,027 & 0,48 \\
\hline ROT (Remaining tissues) (\%) & 4,74 & 4,53 & 4,10 & 5,54 & $\hat{\mathrm{Y}}=4,64$ & 0,527 & 0,46 \\
\hline
\end{tabular}

$\hat{Y}=$ variável dependente; $x$ = nível de feno de flor-de-seda; $R^{2}=$ coeficiente de determinação.

$\hat{\mathrm{Y}}=$ dependent variable, $X=$ independent variable (\% of silk flower hay in the diet), and $R^{2}=$ coefficient of determination.

Tabela 5 - Médias e equações de regressão para a musculosidade da carcaça determinada por meio da relação músculo:osso (M:O), do índice de musculosidade da perna (IMP) e da área de olho-do-lombo (AOL) de cordeiros Santa Inês alimentados com dietas contendo níveis crescentes de feno de flor-de-seda

Table 5 - Means and regression equations for carcass muscularity estimated from the muscle to bone ratio (M:B), leg muscle index (LMI) and loin eye area (LMA) in Santa Inês lambs fed diets with different ratios of silk flower hay to forage sorghum hay

\begin{tabular}{|c|c|c|c|c|c|c|c|}
\hline & \multicolumn{4}{|c|}{$\begin{array}{c}\text { Nível de feno de flor-de-seda (\%) } \\
\text { Level of silk flower hay (\%) }\end{array}$} & \multirow[t]{2}{*}{$\begin{array}{l}\text { Equação de regressão } \\
\text { Regression equation }\end{array}$} & \multirow[t]{2}{*}{$\mathrm{P}$} & \multirow[t]{2}{*}{$\mathrm{R}^{2}$} \\
\hline & 0 & 33 & 66 & 100 & & & \\
\hline $\mathrm{M}: \mathrm{O}^{1}(M: B)$ & 2,81 & 2,88 & 2,41 & 2,22 & $\hat{\mathrm{Y}}=2,90-0,007 \mathrm{X}$ & 0,0017 & 0,39 \\
\hline $\operatorname{IMP}(L M I)$ & 0,35 & 0,36 & 0,32 & 0,31 & $\hat{\mathrm{Y}}=0,357-0,0003 \mathrm{X}$ & 0,0040 & 0,35 \\
\hline $\mathrm{AOL}(L M A)\left(\mathrm{cm}^{2}\right)$ & 11,83 & 11,99 & 9,79 & 10,36 & $\hat{\mathrm{Y}}=11,65-0,02 \mathrm{X}$ & 0,0477 & 0,17 \\
\hline
\end{tabular}

$\hat{\mathrm{Y}}=$ variável dependente; $\mathrm{x}$ = nível de feno de flor-de-seda; $\mathrm{R}^{2}=$ coeficiente de determinação.

$\hat{Y}=$ dependent variable, $X=$ independent variable (\% of silk flower hay in the diet), and $R^{2}=$ coefficient of determination 
alta relação pode ser reflexo de ossos mais leves, e não necessariamente de músculos mais pesados, visto que a avaliação da musculosidade da carcaça baseia-se na profundidade dos músculos que circundam o fêmur em relação ao comprimento desse osso.

Apesar do efeito linear decrescente para a AOL, no tratamento com $100 \%$ de FFS, dois animais morreram aos 65 dias do experimento (média de 11,45 kg de PV), provavelmente porque não resistiram à ação tóxica das substâncias antinutricionais presentes no FFS (Mello, 2000; Lira Filho, 2004). Os animais restantes foram abatidos aos 70 dias do experimento e apresentaram 18,4 a 21,8 kg de PV. No tratamento com $66 \%$ de FFS na dieta, apesar de os animais terem sido afetados pelo efeito tóxico do FFS, todos sobreviveram e apresentaram 15,8 a 29,0 kg de PV.

Segundo Müller (1980), a AOL, isoladamente, não tem correlação alta com a proporção de músculos da carcaça, mas, se avaliada em conjunto com outras características de carcaça, auxilia na avaliação do grau de rendimento de cortes desossados. Os animais dos tratamentos com $0 \mathrm{e}$ $33 \%$ de FFS apresentaram, respectivamente, 11,83 e $11,99 \mathrm{~cm}^{2}$ de AOL, compatíveis com carcaças de alta qualidade, segundo Jones et al. (1984) e Macedo (2000).

Os valores obtidos para AOL neste experimento $(9,79$ a $11,99 \mathrm{~cm}^{2}$ ) foram próximos aos obtidos por Osório et al. (1999), Kirton et al. (1995) e Neres et al. (2001) em cordeiros de diferentes raças. Esses autores obtiveram valores de 11,$99 ; 9,5$ e $10,84 \mathrm{~cm}^{2}$, respectivamente, superiores aos encontrados por Gonzaga et al. (2006) e Pinto (2003), que, estudando cordeiros deslanados Morada Nova e Santa Inês em confinamento alimentados com diferentes volumosos, obtiveram valores para AOL de 4,71 a 7,89 $\mathrm{cm}^{2}$ e de 6,52 a $8,10 \mathrm{~cm}^{2}$, respectivamente.

\section{Conclusões}

O aumento dos níveis de feno de flor-de-seda (FFS) na dieta de cordeiros determina redução linear do peso vivo ao abate, dos pesos de corpo vazio, de carcaça quente e de carcaça fria, dos valores absolutos de pescoço, paleta, costela, lombo e perna, dos valores relativos de lombo, costelas e gordura e da musculosidade da carcaça, todavia, resulta em aumento linear dos rendimentos de perna e osso e não interfere nos rendimentos de corpo vazio, de carcaça quente e de carcaça fria.

O feno de flor-de-seda pode ser utilizado em níveis de até $16,5 \%$ da dieta ou como $33 \%$ do volumoso em substituição ao feno de sorgo forrageiro na alimentação de cordeiros para produção de carne. $\mathrm{O}$ fornecimento do feno de flor-de- seda nesses níveis não prejudica a qualidade da carcaça, porém, por ser tóxico, leva a óbito se constituir $100 \%$ da dieta dos animais.

\section{Literatura Citada}

ABBAS, B.A.E.; TAYEB, E.; SULLEIMAN, Y.R. Calotropis procera: feed potential for arid zones. Veterinary Record, v.131, p.132, 1992

AGRICULTURAL AND FOOD RESEARCH COUNCIL - AFRC. Energy and protein requirements of ruminants. Washington: CAB International, 1995. 159p.

AGRICULTURAL RESEARCH COUNCIL - ARC. The nutrient requirements of farm livestock. London: 1980. $351 \mathrm{p}$.

ARAUJO, G.G.L.; MOREIRA, J.N.; TURCO, S.H.N. et al. Características das carcaças de carneiros alimentados com níveis crescentes de feno de maniçoba (Manihot Pseudoglaziovii). In: REUNIÃO ANUAL DA SOCIEDADE BRASILEIRA DE Zootecnia, 1999, Porto Alegre. Anais... Porto Alegre: Sociedade Brasileira de Zootecnia, 1999. (CD-ROM).

CAÑeque, V.; HuIdobRo, F.R.; DOLZ, J.R. Produccion de carne de cordero. Madrid: Ministério de Agricultura, Pesca y Alimentación, 1989. 520p.

CARVALHO, J.B.D.; PEDROSO, J.R.; FIGUEIRÖ, P.R.P. Alguns fatores que afetam o rendimento de carne ovina. Revista Ciência Rural, v.10, p.95-104, 1980.

COLOMER-ROCHER, F.; MORAND-FEHR, P.; KIRTON, A.H. Standard methods and procedures for goat carcass evaluation, jointing and tissue separation. Livestock Production Science, v.17, p.149-159, 1987.

COLOMER, F.; ESPEJO DIAZ, M. Determinación del peso óptimo de sacrificio de los corderos procedentes del cruzamiento Manchego x Rasa Aragonesa en función del sexo. s.1.: Anales Inia, 1971. n.1. p.103-132. (Série Producción Animal).

COSTA, J.C.C.; OSÓRIO, J.C.S; SILVA, C.A.S. et al. Estudo da morfologia e características comerciais em cordeiros não castrados de quatro raças. Revista Científica Rural, v.4, p.105-112, 1999.

CUNHA, E.A.; BUENO, M.S.; SANTOS, L.E. et al. Desempenho e características de carcaça de cordeiros Suffolk alimentados com diferentes volumosos. Ciência Rural, v.31, p.671-676, 2001.

DE BOER, H.; DUMONT, B.L.; POMEROY, R.W. et al. Manual on E.A.A.P. referent methods for the assessment of carcass characteristics in cattle. Livestock Producción Science, v.1, p. 151-164, 1974 .

GARCIA, C.A.; SILVA SOBRINHO, A.G. Desempenho e características das carcaças de ovinos alimentados com resíduo de panificação "biscoito" In: REUNÃO ANUAL DA SOCIEDADE BRASILEIRA DE ZOOTECNIA, 35., 1998. Botucatu. Anais... Botucatu: Sociedade Brasileira de Zootecnia, 1998. p.29.

GONZAGA NETO, S.; SILVA SOBRINHO, A.G.; ZEOLA, N.M.B.L. et al. Características quantitativas da carcaça de cordeiros deslanados Morada Nova em função da relação volumoso:concentrado na dieta. Revista Brasileira de Zootecnia, v.35, p.1487-1495, 2006

JONES, S.D.M.; BURGESS, T.D.; DUPCHAK, K. et al. The growth performance and carcass composition of ram and ewe lambs fed on pasture or in confinement and slaughtered at similar fat ness. Journal of Animal Science, v.64, p.631-640, 1984.

KIRTON, A.H.; CARTER, A.H.; CLARKE, J.N. et al. A comparasion between 15 ram breeds for export lamb production. 1. Live weight, body components, carcass measurements and conposition. New Zeland Journal Agriculture Research, v.38, p.347-60, 1995

KUMAR, S.; DEWAN, S.; SANGRAULA, H. et al. Anti-diarrhoeal activity of the látex of Calotropis procera. Journal Ethnopharmacology, v.76, p.115-118, 2001 
LIRA FILHO, G.E. Valor nutritivo do feno de flor-de-seda (Calotropis procera $S . W$.) na dieta de ovinos deslanados. Areia: Universidade Federal da Paraíba, 2004. 56p. Dissertação (Mestrado em Zootecnia) - Universidade Federal da Paraíba, 2004.

LUCHIARI FILHO, A. Pecuária da carne bovina. São Paulo: BinLife, 2000. 134p.

MACEDO, F.A.F.; SIQUEIRA, E.R.; MARTINS, E.N. et al Qualidade de carcaças de cordeiros Corriedale e mestiços Bergamácia x Corriedale e Hampshire Down x Corriedale, terminados em pastagem e confinamento. Revista Brasileira de Zootecnia, v.29, p.1520-1527, 2000.

MELLO, M.M.; VAZ, F.A.; GONÇALVES, L.C.; SATURNINO, H.M Estudo fitoquímico da Calotropis procera Ait., sua utilização na alimentação de caprinos: Efeitos clínicos e bioquímicos séricos. Revista Brasileira de Saúde e Produção Animal, v.2, p. $15-20,21000$.

MONTARDO, O.V. Alimentos e alimentação do rebanho leiteiro. Guaíba: Agropecuária, 1998. 209p.

MOTTA, O.S.; PIRES, C.C.; SILVA, J.H.S. et al. Avaliação da carcaça de cordeiros da raça texel sob diferentes métodos de alimentação e pesos de abate. Ciência Rural, v.31, p.1051-1056, 2001.

MÜLLER, L. Normas para avaliação de carcaças e concurso de carcaças de novilhos. Santa Maria: Universidade Federal de Santa Maria, 1980. p.31.

NERES, M.A.; MONTEIRO, A.L.G.; GARCIA, C.A. et al. Forma física da ração e pesos de abate nas características de carcaça de cordeiros em creep feeding. Revista Brasileira de Zootecnia, v.30, p.948-954, 2001.

OSÓRIO, J.C.; OSÓRIO, M.T.; JARDIM, P.O. et al. Métodos para avaliação da produção da carne ovina: in vivo, na carcaça e na carne. Pelotas: Universitária, 1998. 107p.

OSÓRIO, J.C.S.; JARDIM, P.O.C.; PIMENTEL, M.A. et al. Produção de carne entre cordeiros castrados e não castrados. 1. Cruzas Hampshire Down x Corriedale. Ciência Rural, v.29, p.135-138, 1999.

OSÓRIO, J.C.S.; OSÓRIO, M.T.M.; OLIVEIRA, N.M. et al. Qualidade, morfologia e avaliação de carcaças. Pelotas: Universitária, 2002. 197p.

PINTO, C.W.C. Avaliação e desempenho de cordeiros Santa Inês alimentados com diferentes volumosos terminados em confinamento. Areia: Universidade Federal da Paraíba, 2003. 56p. Dissertação (Mestrado em Zootecnia) - Universidade Federal da Paraíba, 2003.
PURCHAS, R.W.; DAVIES, A.S.; ABDULLAH, A.Y. An objective measure of muscularity: changes with animal growth and differences between genetic lives of Southdown sheep. Meat Science, v. 30, p.81-94, 1991.

REIS, W.; JOBIM, C.C.; MACEDO, F.A.F. et al. Características da carcaça de cordeiros alimentados com dietas contendo grãos de milho conservados em diferentes formas. Revista Brasileira de Zootecnia, v.30, p.1308-1315, 2001.

SAÑUDO, C.; PIEDRAFITA, J.; SIERRA, I. Estudio de la calidad de la canal y de la carne en animales cruzados Romanov por Rasa Aragonesa, 2. Comparación en el tipo comercial ternasco con Rasa en pureza. In: JORNADAS CIENTÍFICAS DE LA SOCIEDAD ESPAÑOLA DE OVINOTECNIA, 7., 1981, Talavera de La Reina. Actas... Zaragoza: 1981. p.483-489.

SAÑUDO, C.; SIERRA, I. Calidad de la cabal y de la carne en la especie ovina y caprina. Madrid: Monografías del Consejo General de Colegios Veterinario, 1993. p.207-254.

SHARMA, G.K. Calotropis procera and Calotropis gigantea. Indian Journal Veterinary Science and Animal Husbandry, v.4, p.63-74, 1934.

SILVA SOBRINHO, A.G. Body composition and characteristics of carcass from lambs of different genotypes and ages at slaughter. Palmerston North: Massey University, 1999. 54p. Report (Post Doctorate in Sheep Meat Production) - Massey University, 1999.

SILVA, L.F.; PIRES, C.C.; ZEPPENFELD, C.C. et al. Crescimento de regiões da carcaça de cordeiros abatidos com diferentes pesos. Ciência Rural, v.30, p.481-484, 2000.

SHIVKAR, Y.M; KUMAR, V.L. Anthelmintic activity of the latex of Calotropis procera. Biology Pharmaceutical, v.41, p.263265, 2003.

STATISTIC ANALYSIS SYSTEM - SAS. User's guide: statistic. 6.ed. Cary: 1996. 956p.

TULLOOH, N.M. The carcass composition of the sheep, cattle and pigs as functions of body weight. In: SYMPOSIUM OF CARCASS COMPOSITION AND APPRISAL OF MEAT ANimAls, 1963, Melbourne. Proceedings... Melbourne: Melbourne University (C.I.R.O., Melbourne), 1963. 